ORIGINAL ARTICLE

\title{
Prevalence of Low Birth Weight and Prematurity and Associated Factors in Neonates in Ethiopia: Results from a Hospital-based Observational Study
}

\author{
Melkamu Berhane ${ }^{1 *}$, Netsanet Workineh ${ }^{1}$, Tsinuel Girma ${ }^{1}$, Ruth Lim $^{2}$, \\ Katherine J Lee ${ }^{2,3}$, Cattram D Nguyen ${ }^{2,3}$, Eleanor Neal ${ }^{2,3}$, Fiona M Russell ${ }^{2,3}$,
}

\footnotetext{
OPEN ACCESS

Citation: Melkamu Berhane, Netsanet Workineh, Tsinuel Girma, et al. Prevalence of low birth weight and prematurity and associated factors in neonates in Ethiopia: results from a hospital-based observational study. Ethiop J Health Sci. 2019; 29(6):677.doi:http://dx.doi.org/10.4314/ej hs.v29 i6.5

Received: May 02, 2019

Accepted: September 10, 2019

Published: November 1, 2019

Copyright: (C2019 Melkamu Bi, et al.

This is an open access article distributed under the terms of the Creative Commons Attribution License, which permits unrestricted use, distribution, and reproduction in any medium, provided the original author and source are credited. Funding: This research was funded by the International Pediatric Association and Murdoch Children's Research Institute.

Competing Interests: The authors declare that this manuscript was approved by all authors in its form and that no competing interest exists.

Affiliation and Correspondence:

${ }^{1}$ Jimma University, Department of

Pediatrics and Child Health

${ }^{2}$ Murdoch Children's Research

Institute, The Royal Children's

Hospital, Melbourne, Australia

${ }^{3}$ Department of Pediatrics, The

University of Melbourne, Melbourne,

Australia

*Email: melkamuberhane@yahoo.com
}

\section{ABSTRACT}

BACKGROUND: Low birth weight and prematurity are associated with increased morbidity, mortality and multiple short and longterm complications, exerting impacts on the individual, the families, the community and the health care system. Fetal, maternal and environmental factors have been associated with low birth weight and prematurity, based primarily on researches from high-income countries. It is unknown whether these risk factors are the same in low and middle income countries. The aims of this study are to determine the prevalence of low birth weight and prematurity and associated factors in Jimma University Specialized Hospital, Ethiopia.

METHODS: This observational study was conducted at Jimma University Specialized Hospital, Ethiopia, from December 2014 to September 2016. Multivariable logistic regression was used to determine the associated factors, with results reported as odds ratios (OR) and $95 \%$ confidence intervals (CI).

RESULTS: The prevalence of low birth weight and prematurity were $14.6 \%$ and $10.2 \%$, respectively. The mean birth weight was 2,975g (standard deviation 494). Prematurity (OR 23.54, 95\% CI 15.35-36.08, $p<0.001)$ and unmarried marital status (OR 5.73, 95\%CI 1.61-20.40, $p=0.007)$ were positively associated with low birth weight. Female sex (OR 1.69, 95\%CI 1.18-2.42, $p=0.004)$ and unmarried marital status (OR 4.07, 95\%CI 1.17-14.14, $p=0.027$ ) were positively associated with prematurity.

CONCLUSION: The prevalence of lower birth weight and prematurity in this study is lower than other studies reported from similar facilities. Prematurity and unmarried marital status are associated with $L B W$ whereas female sex and unmarried marital status are associated with prematurity in this population.

Key words: prematurity, low birth weight, newborn 


\section{INTRODUCTION}

Low birth weight (LBW, birth weight $<2,500$ g) and prematurity (gestational age $<37$ weeks) are major contributors of neonatal and infant mortality and morbidity worldwide (5). However, the majority of the cases of both LBW and premature births occur in low- and middle-income countries (LMICs) (2-4). LBW babies have twenty times higher neonatal morbidity than babies weighing $\geq 2500 \mathrm{~g}(5,6)$. In LMICs, LBW and/or premature babies who survive neonatal and infancy periods, have estimated prevalence of any neurodevelopmental impairment, cognitive impairment, and cerebral palsy of $21.4 \%$ (11.6-30.8), $16.3 \%$ (6.3-29.6) and $11.2 \%(5.9-16.1)$, respectively (1). Further, LBW and prematurity are associated with increased vulnerability to infectious diseases, impaired growth, and an increased incidence of chronic diseases in later life, including type II diabetes mellitus, hypertension, chronic renal disease and chronic lung disease (6-8). Given these outcomes, prematurity and LBW are priority public health concerns as both have ongoing impacts on the families, the community and the health system, as well as the individual (2).

Risk factors for LBW and prematurity relate to the fetus, maternal health, and the environment in which the mother lives $(2,5,9,10)$. Previous studies have found that female gender, birth order, and presence of multiple gestations are risk factors for LBW (1). Maternal risk factors for LBW and preterm births include socio-demographic factors (age $<18$ and $>35$, low family income, rural residence, and low/no maternal education); nutritional and anthropometric factors (inadequate maternal diet, inadequate weight gain during pregnancy, short stature and poor nutritional status); lifestyle during pregnancy (alcohol consumption and tobacco smoking) and presence of medical illnesses (malaria, syphilis, hypertension and anemia). Obstetric risk factors of LBW and prematurity include having prior history of LBW/preterm infant, bad obstetric history including previous stillbirth or early neonatal death, short birth interval, placenta previa, placental abruption and lack of adequate prenatal care. Additionally, mothers living in deprived socioeconomic conditions, mothers involved in physically demanding activities and mothers experiencing physical and/or psychological abuse are more likely to give birth to LBW and/or preterm infants $(5,9-11)$.

Although there is existing knowledge on the prevalence and risk factors for LBW and prematurity, this has predominantly been from high-income countries. In contrast, few studies have been undertaken to determine the prevalence and risk factors of LBW and prematurity in LMICs such as Ethiopia (1, 12-16). Health facility-based studies have found LBW prevalence from as low as $6.3 \%$ in Tigray (northern part of Ethiopia) to up to $22.5 \%$ in Jimma (south-western part) (14-16), whereas community-based studies have shown a relatively higher prevalence of LBW of up to $28 \%$ (14-16). Regarding prematurity, prevalence ranging from $4.4 \%$ to $25.9 \%$ have been seen in different studies conducted in the different parts of the country (12, 17). Factors associated with LBW in these studies included maternal age $(<20$ years and $>40$ years), rural residence, multiple pregnancy, presence of maternal chronic illness, maternal weight $<50 \mathrm{~kg}$, maternal weight loss during pregnancy, poverty, poor nutritional status, and being a victim of physical violence during the pregnancy. Inadequate antenatal care (ANC) follow up and female sex of the infant were also among the factors found to be associated with $\operatorname{LBW}(13,15$, 16). Regarding the factors associated with prematurity in Ethiopia, pregnancy induced hypertension and maternal HIV infection have been shown to be associated with preterm birth (12). Although these few studies have been conducted on prematurity and LBW in Ethiopia, the prevalence and associated factors could vary over time as well as by location and hence it is important to have an up-to-date data which reflect the local situation. Hence, this study was conducted with the aim of determining the prevalence of prematurity and LBW and associated factors in Jimma University Specialized Hospital (JUSH), Ethiopia, a settings with high prevalence of LBW and prematurity.

\section{MATERIALS AND METHODS}

Study setting: The study used data from a hospital-based prospective cohort study conducted in JUSH obstetric and neonatal wards from

DOI: http://dx.doi.org/10.4314/ejhs.v29i6.4 
December 2014 to September 2016. JUSH is the only referral hospital in South West Ethiopia for high-level maternal and neonatal care. JUSH has 5,000 to 6,000 deliveries annually.

Study design and procedures: The study was designed to determine the predictive value of foot length, chest circumference and mid-upper arm circumference taken within 24 hours of birth and 5 days of life to predict mortality in the first six weeks of life and identify preterm and LBW infants. As part of this study, data were collected on potential risk factors for infant mortality before six weeks of age. All study procedures were undertaken according to Good Clinical Practice. Following written informed consent, all live born babies who were approached within 24 hours of life and who fulfilled the inclusion criteria were recruited. We opportunistically use data from this study to address the aims of the current manuscript. The newborns that didn't have their birth weight and/or gestational age determined were excluded from the current study.

Trained study nurses administered interviewer-led questionnaires shortly after birth to collect maternal obstetric (gravidity, parity, and number of antenatal visits), socio-demographic (age, ethnicity, marital status, religion, maternal education) and household data, including number of people sleeping in the household, main source of drinking water, and house hold assets (electricity, radio, television, watch, refrigerator, car, bicycle, motor bike, cart and mobile phone). Study paediatricians collected neonatal data, including sex, birth weight, and gestational age. Birth weight of the newborns was measured once using calibrated digital weighing scale (Salter MiBABY) to the nearest $10 \mathrm{~g}$ within 24 hours of life and newborns were classified as LBW $(<2,500 \mathrm{gm})$ or not LBW $(\geq 2,500 \mathrm{gm})$. Gestational age was estimated by using one or more of the three methods: last normal menstrual period (LNMP), early first trimester ultrasound and/or the new Ballard score (NBS). For the sake of this study, we used the NBS estimate of gestational age and classified the newborns as preterm $(<37$ weeks) or not preterm ( $\geq 37$ weeks).

Data were collected on study-specific case report forms and were entered into Epidata version 3.1
(18). Double data entry and monthly validation of the entered data were conducted in order to assure data quality. Additionally, data were checked regularly for completeness and accuracy, and corrections were made accordingly.

Statistical analysis: Data were cleaned and analyzed in Stata 15.1. Socio-economic scores (SES) were constructed by combining householdlevel information on living standards, including household assets (electricity, radio, television, watch, refrigerator, car, bicycle, motorbike, cart, mobile telephone, number of people sleeping in the household), source of water supply (piped into dwelling/yard, public tap or well, spring, surface water, river, lake, or pond), and main source of cooking fuel (charcoal, wood, dung). Principal components analysis (PCA) was then used to create uncorrelated indices (components) to represent SES made up of weighted combinations of the living standard variables. The first of these indices was grouped into quintiles to reflect SES $(19,20)$. Living standard variables which exhibited no variation (household use of kerosene, gas, straw, dung, and agricultural cropping) between participant households were excluded as they would have been zero weighted, and therefore of no use in differentiating SES. Maternal (age, ethnicity, marital status, religion, education, gravidity, parity, previous child deaths, and number of antenatal visits), familial (number of people sleeping in the house, main source of drinking water, and socioeconomic score), and infant (sex, birth weight, and prematurity) characteristics were summarized by counts and percentages.

Univariable and multivariable logistic regression models were built to estimate the association between the risk factors and LBW and prematurity. Risk factors included in regression models were prematurity, sex, maternal age, marital status, highest level of maternal education, wealth quintile, gravidity, parity, number of previous child deaths, and number of antenatal care (ANC) visits. We treated prematurity as an independent variable in the analysis of LBW and as a dependent variable in the analysis of prematurity. Empirical variable selection $(p<0.2)$ was used to determine which variables to include

DOI: http://dx.doi.org/10.4314/ejhs.v29i6.4 
in the multivariable models. Results are reported as odds ratios (ORs) with $95 \%$ confidence intervals $(\mathrm{CI})$ and the corresponding p-values. As sources of water and number of people sleeping in the household were included in PCA to generate SES index, they were not considered in the regression models.

Sample size: The sample size $(n=1,486)$ was selected based on the number of newborns necessary to estimate the sensitivity of anthropometric tools to predict 6-week mortality in Ethiopia, the original aim of the study. We used the same sample for the current analysis.

The study was undertaken according to the protocol approved by Jimma University Ethics
Review Committee and The University of Melbourne, Human Research Ethics Committee (Ethics ID: 1442168) prior to commencing of the study.

\section{RESULTS}

During the study period, there were 4,143 deliveries in the hospital, of which 1,486 were enrolled into the study, and 1,390 (93.5\%) and $1,400(94.2 \%)$ had their birth weight and gestational age by the NBS determined respectively. The rest were clinically unstable for anthropometric and GA assessment (See Figure $1)$.

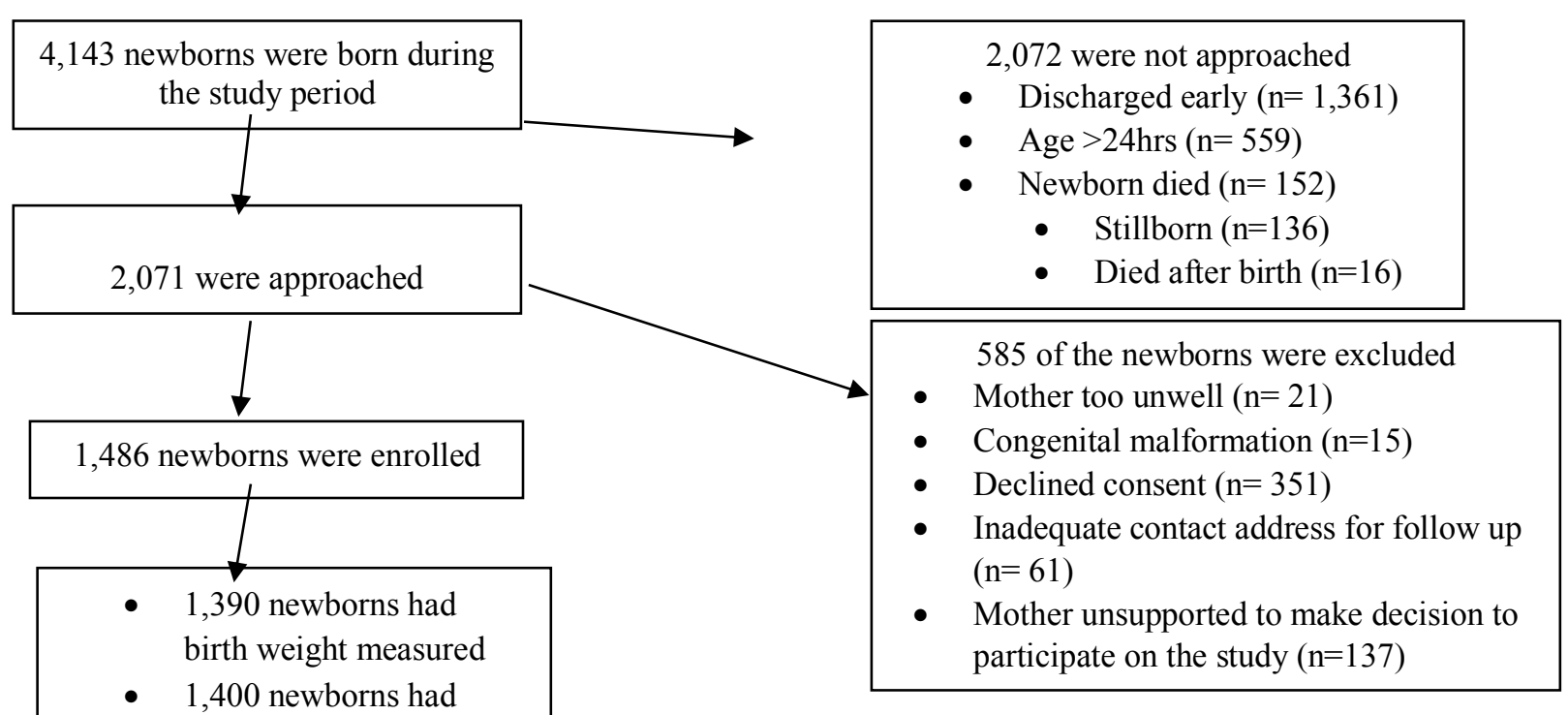

Figure 1: Flow chart showing enrollment of participants at the Jimma University Specialized Hospital from 2014 to 2016.

Maternal socio-demographics and obstetric characteristics: The majority of the mothers were aged between $18-34$ years $(90.3 \%)$ and married $(99.0 \%)$ (Table 1). Just over two thirds $(70.9 \%)$ were Oromo in ethnicity and Muslim (67.4\%) in religion. One third of the mothers had not been educated beyond primary school $(35.0 \%)$, and $22.7 \%$ were illiterate. For half of the mothers, it was their first pregnancy (gravida I $49.0 \%$, and para I, 51.4\%). Almost all the mothers (96.5\%) had attended ANC follow up, although $28.5 \%$ did not receive the minimum World Health Organization (WHO) recommended 4 visits. Only
$2.0 \%$ of the mothers had ultrasound examination during $\mathrm{ANC}$, of whom only 2 remembered the date the ultrasound examination was conducted. Two hundred $(13.4 \%)$ of the mothers had experienced a previous child death, with $22.5 \%$ of them having more than one child death.

Household characteristics: One quarter of the households $(25.8 \%)$ have more than 5 people sleeping in the house. In $52.0 \%$ of the households the drinking water source was piped into either the yard or dwelling, and $19.3 \%$ retrieved their water from spring, surface water, river or pond (Table $1)$.

DOI: http://dx.doi.org/10.4314/ejhs.v29i6.4 
Table1: Personal and household characteristics of participant mothers at Jimma University Specialized Hospital, $2014-2016(n=1486$, unless otherwise specified $)$.

\begin{tabular}{|c|c|c|c|}
\hline Characteristics & $\begin{array}{c}\text { Total } \\
(n=1,486)\end{array}$ & $\begin{array}{c}\text { LBW } \\
(n=203)\end{array}$ & $\begin{array}{c}\text { Premature } \\
(n=143)\end{array}$ \\
\hline \multicolumn{4}{|l|}{ Maternal age, n (\%) } \\
\hline$<18$ years & $27(1.8)$ & $2(1.0)$ & $2(1.4)$ \\
\hline $18-34$ years & $1342(90.3)$ & $179(88.2)$ & $124(86.7)$ \\
\hline$\geq 35$ years & $117(7.9)$ & $22(10.8)$ & $17(11.9)$ \\
\hline \multicolumn{4}{|l|}{ Ethnicity, n (\%) } \\
\hline Oromo & $1054(70.9)$ & $150(73.9)$ & $112(78.3)$ \\
\hline Amhara & $128(8.6)$ & $14(6.9)$ & $8(5.6)$ \\
\hline Tigre and others & $103(6.9)$ & $8(3.9)$ & $5(3.5)$ \\
\hline Yam & $84(5.7)$ & $12(5.9)$ & $6(4.2)$ \\
\hline Dawuro & $57(3.9)$ & $10(4.9)$ & $4(2.8)$ \\
\hline Kaffa & $60(4.0)$ & $9(4.4)$ & $8(5.6)$ \\
\hline \multicolumn{4}{|l|}{ Marital status, n (\%) } \\
\hline Married or defacto & $1471(99.0)$ & $195(96.1)$ & $139(97.2)$ \\
\hline Widowed, divorced, separated, or never lived together & $15(1.0)$ & $8(3.9)$ & $4(2.8$ \\
\hline \multicolumn{4}{|l|}{ Religion, $\mathrm{n}(\%)$} \\
\hline Muslim & $1002(67.4)$ & $148(72.9)$ & $114(79.7)$ \\
\hline Orthodox Christian & $327(22.0)$ & $33(16.3)$ & $16(11.2)$ \\
\hline Non-orthodox Christian, or other & $157(10.6)$ & $22(10.8)$ & $13(9.1)$ \\
\hline \multicolumn{4}{|l|}{ Maternal education, n (\%) } \\
\hline None & $338(22.7)$ & $63(31.0)$ & $49(34.3)$ \\
\hline Primary & $520(35.0)$ & $75(37.0)$ & $52(36.4)$ \\
\hline Secondary & $358(24.1)$ & $36(17.7)$ & $24(16.8)$ \\
\hline Higher, technical, or vocational & $270(18.2)$ & $29(14.3)$ & $18(12.6)$ \\
\hline \multicolumn{4}{|l|}{ Number of people sleeping in the house, $n(\%)$} \\
\hline$<5$ & $1103(74.2)$ & $140(69.0$ & $87(60.8)$ \\
\hline$\geq 5$ & $383(25.8)$ & $63(31.0)$ & $56(39.2)$ \\
\hline \multicolumn{4}{|l|}{ Main source of drinking water, $n(\%)$} \\
\hline Piped to dwelling or yard & $773(52.0)$ & $82(40.4)$ & $53(37.1)$ \\
\hline Public tap or well & $426(28.7)$ & $73(36.0)$ & $49(34.3)$ \\
\hline Spring, surface water, river, lake, or pond & $287(19.3)$ & $48(23.6)$ & $41(28.7)$ \\
\hline \multicolumn{4}{|c|}{ Socioeconomic score by wealth quintile derived via PCA, n (\%) } \\
\hline Poorest & $298(20.0)$ & $27(13.3)$ & $17(11.9)$ \\
\hline Second & $303(20.4)$ & $33(16.3)$ & $20(14.0)$ \\
\hline Middle & $293(19.7)$ & $41(20.2)$ & $29(20.3)$ \\
\hline Fourth & $301(20.3)$ & $40(19.7)$ & $31(21.7)$ \\
\hline Richest & 291(19.6) & $62(30.5)$ & $46(32.1)$ \\
\hline \multicolumn{4}{|l|}{ Gravida, n (\%) } \\
\hline Primigravida & $728(49.0)$ & $92(45.3)$ & $51(35.7)$ \\
\hline Multigravida ( $\geq 2$ pregnancies) & $758(51.0)$ & $111(54.7)$ & $92(64.3)$ \\
\hline \multicolumn{4}{|l|}{ Parity, n (\%) } \\
\hline Primiparous & $764(51.4)$ & $96(47.3)$ & $52(36.4)$ \\
\hline Multiparous (2-4 births) & $541(36.4)$ & 75 (36.9) & $64(44.8)$ \\
\hline Grand multipara ( $\geq 5$ births) & $181(12.2)$ & $32(15.8)$ & $27(18.9)$ \\
\hline \multicolumn{4}{|l|}{ Previous child deaths, n (\%) } \\
\hline 0 & $1286(86.6)$ & $171(84.2)$ & $120(83.9)$ \\
\hline 1 & $155(10.4)$ & $25(12.3)$ & $20(14.0)$ \\
\hline$\geq 2$ & $45(3.0)$ & $7(3.5)$ & $3(2.1)$ \\
\hline \multicolumn{4}{|l|}{ Number of antenatal care visits, $n(\%)$} \\
\hline$\geq 4$ visits & $946(68.0)$ & $118(58.1)$ & $85(59.4)$ \\
\hline$\overline{1}-3$ visits & $396(28.5)$ & $72(35.5)$ & $51(35.7)$ \\
\hline 0 visits & $48(3.5)$ & $13(6.4)$ & $7(4.9)$ \\
\hline
\end{tabular}

DOI: http://dx.doi.org/10.4314/ejhs.v29i6.4 
Newborn-related data: In this study, the proportion of males was slightly higher $(55.1 \%)$ than females. The mean birth weight was 2,975gm, (SD 494). Out of the 1,390 newborns who had their birth weight determined, 203 $(14.6 \%)$ were LBW $(<2,500 \mathrm{gm})$. Few infants $(10.2 \%)$ were preterm $(<37$ weeks) (Table 2$)$. We have gestational age for 1,400 newborns and birth weight for 1390 newborns. Out of the 203 LBW newborns, $62(30.5 \%)$ were small for gestational age and $140(68.9 \%)$ were appropriate for gestational age. One hundred forty three $(10.2 \%)$ of the infants were preterm $(<37$ weeks) (Table 2$)$. The mean birth weight for the LBW and preterm babies was 2,170 (SD 258) and 2,310 (SD 816), respectively, whereas it was 3,112 (SD 380) and 3,070 (SD 661) for the non-LBW and non-preterm infants, respectively. Similarly, the mean gestational age for the LBW and preterm babies was 36.9 (SD 2.4) and 34.6 (SD 1.6), whereas it was 39.4 (SD 1.5) and 39.4 (SD 1.4) for the nonLBW and non-preterm infants.

Table 2: Characteristics of neonates born to participant mothers at Jimma University Specialized Hospital, 2014 - $2016(n=1486$, unless otherwise specified).

\begin{tabular}{cc}
\hline Characteristic & Summary statistic \\
\hline Sex, $\mathbf{n}(\mathbf{\%})$ & \\
Male & $818(55.1)$ \\
Female & $668(44.9)$ \\
Birth weight, $\mathbf{n}(\%)$ & $\mathrm{n}=1390$ \\
$\geq 2500$ gm (normal birth weight/macrosomia) & $1187(85.4)$ \\
$<2500$ gm & $203(14.6)$ \\
$1500-2499$ gms (LBW) & $199(14.3)$ \\
$<1500$ gm (very LBW) & $4(0.3)$ \\
Gestational age by New Ballard Score, $\mathbf{n}(\mathbf{\%})$ & $\mathrm{n}=1400$ \\
$\geq 37$ weeks (term/post-term) & $1257(89.8)$ \\
$<37$ weeks (preterm) & $143(10.2)$ \\
$32-36$ weeks & $141(10.1)$ \\
$<32$ weeks (very preterm) & $2(0.1)$ \\
\hline
\end{tabular}

Factors associated with LBW and prematurity: In the univariable analyses, there was evidence that prematurity (OR 24.35, 95\% CI 16.15-36.70, $\mathrm{p}<0.001$ ), female sex (OR 1.62, 95\% CI 1.20 $2.19, \mathrm{p}=0.002$ ), unmarried marital status (OR 6.92, $95 \%$ CI $2.48-19.29, \quad \mathrm{p}<0.001)$, maternal education (global $\mathrm{p}=0.006$ ), socio-economic index (global $\mathrm{p}<0.001$ ), and number of ANC visits (global $\mathrm{p}=0.001$ ) were positively associated with LBW (Table 3). In the multivariable analysis, there only remained evidence that prematurity (OR 23.54, 95\% CI 15.35-36.08, p<0.001) and marital status (OR 5.73, 95\% CI 1.61 - 20.40, $\mathrm{p}=0.007$ ) were associated with LBW.

For prematurity, in the univariable analysis, there was evidence that female sex (OR 1.71, 95\% CI $1.21-2.43, \mathrm{p}=0.003)$, unmarried marital status
(OR 3.26, 95\% CI $1.02-10.34, \mathrm{p}=0.045)$ maternal education (global $\mathrm{p}=0.002$ ), socioeconomic index (global $=0.001$ ), multigravida (OR 1.78, 95\% CI1.24 - 2.56, $\mathrm{p}=0.002$ ), and parity (global $\mathrm{p}<0.001$ ) were associated with prematurity (Table 4). In the multivariable model, there only remained evidence that female sex (OR 1.69, 95\% CI $1.18-2.42$, $\mathrm{p}=0.004$ ) and unmarried marital status (OR 4.07, 955 CI $1.17-14.14, p=0.027)$ were associated with prematurity.

DOI: http://dx.doi.org/10.4314/ejhs.v29i6.4 
Table 3: Univariable and multivariable odds ratios of potential risk factors for low birth weight in neonates born at Jimma University Specialized Hospital, 2014 - $2016(n=1390)$.

\begin{tabular}{|c|c|c|c|c|}
\hline Characteristics & $\begin{array}{l}\text { Univariable odds } \\
\text { ratio }(95 \% \mathrm{CI})\end{array}$ & $\mathbf{P}$ & $\begin{array}{l}\text { Multivariable odds } \\
\text { ratio }(95 \% \mathrm{CI})\end{array}$ & $\mathbf{P}$ \\
\hline \multicolumn{5}{|l|}{ Gestational age by NBS } \\
\hline$\geq 37$ weeks (term/post-term) & ref & & ref & \\
\hline$<37$ weeks (preterm) & $24.35(16.15-36.70)$ & $<0.001$ & $23.54(15.35-36.08)$ & $<0.001$ \\
\hline \multicolumn{5}{|l|}{ Sex } \\
\hline Male & ref & & ref & \\
\hline Female & $1.62(1.20-2.19)$ & 0.002 & $1.40(0.98-2.00)$ & 0.07 \\
\hline \multicolumn{5}{|l|}{ Maternal age } \\
\hline $18-34$ years & $r e f$ & & ref & \\
\hline$<18$ years & $0.55(0.13-2.35)$ & 0.14 & $0.23(0.03-1.62)$ & 0.18 \\
\hline$\geq 35$ years & $1.56(0.95-2.56)$ & & $1.40(0.75-2.91)$ & \\
\hline \multicolumn{5}{|l|}{ Marital status } \\
\hline Married or defacto & ref & & ref & \\
\hline $\begin{array}{l}\text { Widowed, divorced, separated, } \\
\text { or never lived together }\end{array}$ & $6.92(2.48-19.29)$ & $<0.001$ & $5.73(1.61-20.40)$ & 0.007 \\
\hline \multicolumn{5}{|l|}{ Maternal education } \\
\hline Higher, technical, or vocational & ref & & ref & \\
\hline Secondary & $0.90(0.54-1.52)$ & & $0.76(0.41-1.42)$ & \\
\hline Primary & $1.33(0.84-2.10)$ & 0.006 & $0.95(0.51-1.77)$ & \\
\hline None & $1.85(1.15-2.97)$ & & $0.95(0.45-2.01)$ & 0.79 \\
\hline \multicolumn{5}{|l|}{$\begin{array}{l}\text { Socioeconomic index by wealth } \\
\text { quintile }\end{array}$} \\
\hline Richest & ref & & ref & \\
\hline Fourth & $1.23(0.72-2.10)$ & & $1.16(0.61-2.19)$ & \\
\hline Middle & $1.56(0.93-2.62)$ & 0.001 & $1.16(0.59-2.26)$ & 0.67 \\
\hline Second & $1.48(0.88-2.49)$ & & $1.07(0.54-2.14)$ & \\
\hline Poorest & $2.56(1.57-4.16)$ & & $1.57(0.76-3.23)$ & \\
\hline \multicolumn{5}{|l|}{ Gravida } \\
\hline Primigravida & ref & & & \\
\hline Multigravida & $1.14(0.85-1.54)$ & 0.39 & & \\
\hline \multicolumn{5}{|l|}{ Parity } \\
\hline Primiparous & ref & & ref & \\
\hline Multiparous (2-4 births) & $1.08(0.78-1.50)$ & 0.26 & $0.79(0.53-1.19)$ & 0.34 \\
\hline Grand multipara ( $\geq 5$ births) & $1.45(0.93-2.25)$ & & $0.64(0.33-1.26)$ & \\
\hline \multicolumn{5}{|l|}{ Previous child deaths } \\
\hline 0 & ref & & & \\
\hline$\geq 1$ & $1.28(0.85-1.94)$ & 0.24 & & \\
\hline \multicolumn{5}{|l|}{ Number of antenatal care visits } \\
\hline$\geq 4$ & ref & & ref & \\
\hline$\overline{1}-3$ & $1.56(1.13-2.15)$ & & $1.40(0.94-2.10)$ & 0.17 \\
\hline 0 & $2.61(1.34-2.07)$ & 0.001 & $1.73(0.74-4.04)$ & \\
\hline
\end{tabular}


Table 4: Univariable and multivariable odds ratios for potential risk factors of prematurity in neonates born at Jimma University Specialized Hospital $(\mathrm{n}=1400)$.

\begin{tabular}{|c|c|c|c|c|}
\hline Characteristic & $\begin{array}{c}\text { Univariable odds } \\
\text { ratio }(95 \% \mathrm{CI})\end{array}$ & $\mathbf{P}$ & $\begin{array}{l}\text { Multivariable odds } \\
\text { ratio }(95 \% \text { CI })\end{array}$ & $\mathbf{P}$ \\
\hline \multicolumn{5}{|l|}{ Sex } \\
\hline Male & ref & & ref & \\
\hline Female & $1.71(1.21-2.43)$ & 0.003 & $1.69(1.18-2.42)$ & 0.004 \\
\hline \multicolumn{5}{|l|}{ Maternal age } \\
\hline $18-34$ years & ref & & ref & \\
\hline$<18$ years & $0.84(0.19-3.61)$ & 0.13 & $0.87(0.19-3.95)$ & 0.70 \\
\hline$\geq 35$ years $^{c}$ & $1.74(1.01-3.02)$ & & $1.31(0.69-2.49)$ & \\
\hline \multicolumn{5}{|l|}{ Marital status } \\
\hline Married or defacto & ref & & ref & \\
\hline $\begin{array}{l}\text { Widowed, divorced, separated, or } \\
\text { never lived together }\end{array}$ & $3.26(1.02-10.34)$ & 0.05 & $4.07(1.17-14.14)$ & 0.03 \\
\hline \multicolumn{5}{|l|}{ Maternal education } \\
\hline Higher, technical, or vocational & ref & & ref & \\
\hline Secondary & $0.98(0.52-1.86)$ & & $0.78(0.40-1.52)$ & \\
\hline Primary & $1.50(0.86-2.62)$ & 0.002 & $0.89(0.46-1.71)$ & 0.89 \\
\hline None & $2.35(1.33-4.14)$ & & $0.92(0.43-1.97)$ & \\
\hline \multicolumn{5}{|l|}{$\begin{array}{l}\text { Socioeconomic score by wealth } \\
\text { quintile }\end{array}$} \\
\hline Richest & ref & & ref & \\
\hline Fourth & $1.17(0.60-2.28)$ & & $1.21(0.60-2.42)$ & \\
\hline Middle & $1.76(0.94-3.28)$ & 0.001 & $1.86(0.92-3.76)$ & 0.87 \\
\hline Second & $1.85(1.00-3.43)$ & & $1.89(0.92-3.88)$ & \\
\hline Poorest & $2.97(1.66-5.33)$ & & $2.65(1.25-5.59)$ & \\
\hline \multicolumn{5}{|l|}{ Gravida } \\
\hline Primigravida & ref & & ref & \\
\hline Multigravida & $1.78(1.24-2.56)$ & 0.002 & $0.38(0.05-2.86)$ & 0.35 \\
\hline \multicolumn{5}{|l|}{ Parity } \\
\hline Primiparous & ref & & ref & \\
\hline Multiparous (2-4 births) & $1.79(1.22-2.63)$ & & $4.98(0.66-37.47)$ & 0.23 \\
\hline Grand multipara $(\geq 5)$ & $2.36(1.43-3.88)$ & $<0.001$ & $3.92(0.49-31.09)$ & \\
\hline \multicolumn{5}{|l|}{ Previous child deaths } \\
\hline 0 & ref & & & \\
\hline$\geq 1$ & $1.30(0.81-2.10)$ & 0.27 & & \\
\hline \multicolumn{5}{|l|}{ Number of antenatal care visits } \\
\hline$\geq 4$ & ref & & ref & \\
\hline $1-3$ & $1.49(1.03-2.15)$ & 0.07 & $1.26(0.85-1.87)$ & 0.47 \\
\hline 0 & $1.70(0.74-2.90)$ & & $0.96(0.39-2.33)$ & \\
\hline
\end{tabular}

DOI: http://dx.doi.org/10.4314/ejhs.v29i6.4 


\section{DISCUSSION}

In our study, we have determined the prevalence of LBW and prematurity from mothers who gave birth in one of the tertiary hospitals in Ethiopia. The prevalence of LBW in our study $(14.6 \%)$ is slightly lower than the prevalence seen in other studies conducted in Sub-Saharan Africa and Ethiopia, which showed LBW prevalence of $16.7 \%$ in a retrospective study in Zimbabwe, $17.1 \%$ in a hospital-based study in Gondar, $22.5 \%$ in a study conducted in health centers and hospitals in Jimma Town, and $28.3 \%$ in a community-based study in Kersa, Eastern Ethiopia $(5,14,15,21)$. The differences seen in the prevalence of LBW in these studies could be explained by the difference in the time the studies were conducted, as well as differences in the methods used including the study subjects and the study settings. The prevalence of LBW found in our study is higher than that found in other studies conducted in Pakistan $(9.9 \%)$ and the northern part of Ethiopia $(6.3 \%)$, as well as the Ethiopian Demographic and Health Survey (EDHS) report of $13 \%(11,16,22)$. These differences could again be explained by the differences in the timing of the studies as well as the methodologies used. In the north Ethiopian study, the study was conducted at primary health facilities which are less likely to give services to the mothers with complicated pregnancies, and weight measurements were recorded to the nearest $100 \mathrm{~g}$ which could lead to under estimation of LBW; the EDHS's assessment of birth weight is mainly dependent on maternal report of small baby at birth than an actual birth weight measurement. In addition, our exclusion criteria could have also contributed to these differences since we did not include babies who were discharged early who were assumed to have a normal birth weight.

The factors found to be independently associated with LBW in our study were prematurity, which is to be expected, and marital status. Mothers who delivered before 37 weeks of gestation had almost 24 times the odds of delivering LBW babies than mothers who delivered at or after 37 weeks of gestation. This finding is similar to the other reports which, unsurprisingly, identified prematurity as one of the predictors of LBW (23). Unmarried mothers had over 5 times the odds of giving birth to LBW infants than their married counterparts which is also in line with other studies $(2,3)$. This might indicate the need to target this group of mothers during ANC follow up so that interventions can be implemented to reduce the burden of LBW birth.

The prevalence of prematurity in this study was $10.2 \%$ which is similar to that reported from a study conducted in Brazil (11.5\%) (24), but it is lower than other studies conducted in Kenya $(18.3 \%)$ and Jimma $(25.9 \%)(17,21)$. The difference in these estimates could be explained by the differences in the study design and the setting of the studies (in the Jimma study, every third mother was included whereas the Kenyan study was conducted in one of the huge hospitals in the capital, where lots of mothers with complicated pregnancies deliver annually). Our estimated prevalence of prematurity is higher than that found in a study conducted in Gondar (northern part of Ethiopia) where the prevalence of prematurity was $4.4 \%$ (12). This may be due to the methods used (they recruited every third mother) and the study setting (they included mothers attending primary health facilities only), the latter of which could potentially underestimate the prevalence of prematurity.

Although our study found evidence that a number of factors were correlated with prematurity in univariable analysis, in the multivariable analysis, there was only evidence that female sex and unmarried marital status were independently associated with prematurity. This is similar to previous studies which have found unmarried mothers to have adverse birth outcome including prematurity $(25,26)$, but contrary to other studies which have found male sex to be associated with prematurity $(27,28)$.

The strengths of our study include the prospective nature of the study and the relatively large sample size. The limitations include the use of secondary data which was collected for another purpose, and the fact that we did not collect data on some of the key factors associated with LBW and prematurity, such as maternal medical conditions. Additionally, the exclusion criteria 
used might also be a limitation of the study and underestimated the prevalence of LBW and prematurity as we only included live births with no gross congenital abnormalities as well as still births which could possibly be associated with LBW or prematurity. Besides, this study was done in a single institution which might limit generalization of the findings of the study. Despite these limitations, this paper adds important information to the currently available data on LBW and prematurity, in particular providing an up-to-date estimate of the prevalence of these two conditions in Jimma, Ethiopia.

In conclusion, the prevalence of LBW and prematurity found in our study is lower than that found in studies reported from similar facilities, although it is higher than other studies conducted in primary health care facilities. In this study, we found evidence that prematurity and the mother being unmarried are independently associated with LBW, whereas female sex and unmarried marital status are associated with prematurity.

\section{ACKNOWLEDMENTS}

First and foremost, we would like to thank all the participants of the study who gave us their consent to take part on the study. Secondly, we would like to thank all the staff of JUCAN Research Partnership and staff of the labor and delivery units as well as the neonatal ICU of JUSH for their contribution during the data collection. We would also thank the International Pediatric Association and Murdoch Children's Research Institute for financially supporting this study.

\section{REFERENCES}

1. Milner KM, Neal EF, Roberts G, Steer AC, Duke T. Long-term neurodevelopmental outcome in high-risk newborns in resourcelimited settings: a systematic review of the literature. Paediatrics and international child health. 2015;35(3):227-42.

2. World Health Organization (WHO). Born too soon: the global action report on preterm birth. 2012.

3. Cutland CL, Lackritz EM, Mallett-Moore T, Bardají A, Chandrasekaran R, Lahariya C, et al. Low birth weight: Case definition \& guidelines for data collection, analysis, and presentation of maternal immunization safety data. Vaccine. 2017;35(48):6492-500.

4. Harrison MS, Goldenberg RL, editors. Global burden of prematurity. Seminars in fetal and neonatal medicine; 2016: Elsevier.

5. Wardlaw TM. Low birthweight: country, regional and global estimates: Unicef; 2004.

6. Goldenberg RL, Culhane JF. Low birth weight in the United States. The American journal of clinical nutrition. 2007;85(2):584s-90s.

7. Lorenz JM, Wooliever DE, Jetton JR, Paneth N. A quantitative review of mortality and developmental disability in extremely premature newborns. Archives of pediatrics \& adolescent medicine. 1998;152(5):425-35.

8. Ballot DE, Potterton J, Chirwa T, Hilburn N, Cooper PA. Developmental outcome of very

DOI: http://dx.doi.org/10.4314/ejhs.v29i6.4 
low birth weight infants in a developing country. BMC pediatrics. 2012;12(1):11.

9. Coutinho PR, Cecatti JG, Surita FG, Souza JPd, Morais SSd. Factors associated with low birth weight in a historical series of deliveries in Campinas, Brazil. Revista da Associação Médica Brasileira. 2009;55(6):692-9.

10. Feresu SA, Harlow SD, Woelk GB. Risk factors for low birthweight in Zimbabwean women: a secondary data analysis. PloS one. 2015;10(6):e0129705.

11. Badshah S, Mason L, McKelvie K, Payne R, Lisboa PJ. Risk factors for low birthweight in the public-hospitals at Peshawar, NWFPPakistan. BMC public health. 2008;8(1):197.

12. Gebreslasie K. Preterm Birth and Associated Factors among Mothers Who Gave Birth in Gondar Town Health Institutions. Advances in Nursing. 2016;2016.

13. Zeleke BM, Zelalem M, Mohammed N. Incidence and correlates of low birth weight at a referral hospital in Northwest Ethiopia. Pan African Medical Journal. 2012;12(1).

14. Tema T. Prevalence and determinants of low birth weight in Jimma Zone, Southwest Ethiopia. East African medical journal. 2006;83(7):366.

15. Assefa N, Berhane Y, Worku A. Wealth status, mid upper arm circumference (MUAC) and antenatal care (ANC) are determinants for low birth weight in Kersa, Ethiopia. PloS one. 2012;7(6):e39957.
16. Teklehaimanot $\mathrm{N}$, Hailu $\mathrm{T}$, Assefa $\mathrm{H}$. Prevalence and factors associated with low birth weight in Axum and Laelay Maichew districts, North Ethiopia: a comparative cross sectional study. Int $J$ Nutr Food Sci. 2014;3(6):560-6.

17. Bekele E, Urigesa F. 14. Prevalence of Gestational Diabetes Mellitus and its Association with Maternal and Neonatal Adverse Outcomes among Mothers who Gave Birth in Hiwot Fana and Dilchora Hospitals, Eastern Ethiopia. Tropical Journal of Obstetrics and Gynecology. 2018;35(1):58-61.

18. TB Christiansen, Lauritsen J. omprehensive Data Management and Basic Statistical Analysis System. Odense, Denmark: EpiData Association; 2010.

19. Pearson K. Principal components analysis. The London, Edinburgh, and Dublin Philosophical Magazine and Journal of Science. 1901;6(2):559.

20. Vyas S, Kumaranayake L. Constructing socioeconomic status indices: how to use principal components analysis. Health Policy and Planning. 2006;21(6):459-68.

21. Wagura P, Wasunna A, Laving A, Wamalwa D. Prevalence and factors associated with preterm birth at kenyatta national hospital. $B M C$ pregnancy and childbirth. 2018;18(1):107.

22. Ethiopian Demographic and Health Survey, 2016. Central Statistically Agency. The DHS

DOI: http://dx.doi.org/10.4314/ejhs.v29i6.4 
Program ICF Rockville, Maryland USA. July 2017.

23. Hosain GM, Chatterjee N, Begum A, Saha SC. Factors associated with low birthweight in rural Bangladesh. Journal of tropical pediatrics. 2006;52(2):87-91.

24. do Carmo Leal M, Esteves-Pereira AP, Nakamura-Pereira M, Torres JA, Theme-Filha M, Domingues RMSM, et al. Prevalence and risk factors related to preterm birth in Brazil. Reproductive health. 2016;13(3):127.

25. Shah PS, Zao J, Ali S. Maternal marital status and birth outcomes: a systematic review and meta-analyses. Maternal Child Health Journal. October 2011;15(7):1097-109.

26. Yeani Choi, Gyeongsil Lee, In Gyu Song, Ock JooKim, Sang Min Park.Prevalence of adverse birth outcomes and disparity of unmarried women in South Korea: a systematic review. Journal of Global Health Reports. 2018;2.

27. Jennifer Zeitlin, Marie-Jose'phe SaurelCubizolles, Jaques de Mouzon, Lucile Rivera, Pierre-Yves Ancel, Be'atrice Blondel, et al. Fetal sex and preterm birth: are males at greater risk? Human Reproduction. 2002;17(10):2762.

28. Myrthe J.C.S. Peelen, Brenda M. Kazemier, Anita C.J. Ravelli, Christianne J.M. DE, Groot, Joris A.M. Van Der Post, et al. Impact of fetal gender on the risk of preterm birth, a national cohort study. Nordic Federation of Societies of Obstetrics and Gynecology, Acta
Obstetricia et Gynecologica Scandinavica. 2016;90:1034-1041. 